\title{
Risk models for congenital and pediatric cardiac care: The importance of timing of data collection and selection of outcome variables
}

\author{
Jeffrey P. Jacobs, MD, FACS, FACC, FCCP
}

\footnotetext{
From the Division of Cardiovascular Surgery, Department of Surgery, Johns Hopkins All Children's Heart Institute, Johns Hopkins All Children's Hospital and Florida Hospital for Children, Saint Petersburg, Tampa, and Orlando, Fla; and the Division of Cardiac Surgery, Department of Surgery, Johns Hopkins University School of Medicine, Baltimore, Md.

Disclosures: J.P.J. serves as Chair of the Society of Thoracic Surgeons Workforce on National Databases (http:/ www.sts.org/about-sts/governance-and-leadership/workforces-and-committees/workforce-national-databases) Received for publication April 15, 2017; accepted for publication April 21, 2017; available ahead of print May 26 2017.

Address for reprints: Jeffrey P. Jacobs, MD, FACS, FACC, FCCP, Professor of Surgery and Pediatrics, Johns Hopkins University, Co-Director, Johns Hopkins All Children's Heart Institute, Chief, Division of Cardiovascular Surgery, Director, Andrews/Daicoff Cardiovascular Program, Surgical Director of Heart Transplantation and Extracorporeal Life Support Programs, Johns Hopkins All Children's Hospital and Florida Hospital for Children, 601 Fifth St S, Suite 607, Saint Petersburg, FL 33701 (E-mail: JeffJacobs@jhmi.edu; JeffJacobs@msn. com; http://www.HOPKINSAllChildrens.org/Heart).

J Thorac Cardiovasc Surg 2017;154:629-30

$0022-5223 / \$ 36.00$

Copyright (C 2017 Published by Elsevier Inc. on behalf of The American Association for Thoracic Surgery http://dx.doi.org/10.1016/j.jtcvs.2017.04.053
}

Berger and colleagues ${ }^{1}$ are to be congratulated for their analysis in this issue of the Journal, "Morbidity and Mortality Prediction in Pediatric Heart Surgery: Physiological Profiles and Surgical Complexity." Their multiinstitutional analysis of 1550 patients younger than 18 years undergoing cardiac surgery at 7 sites (with 1 site composed of 2 institutions) assessed the relationship of postoperative mortality and morbidity associated with pediatric cardiac surgery to both physiology-based profiles (as assessed by the Pediatric Risk of Mortality [PRISM] score) and surgical risk scores (as assessed by Risk Adjusted classification for Congenital Heart Surgery [RACHS-1] categories and STAT Mortality Categories). This detailed and thoughtful analysis by Berger and colleagues ${ }^{1}$ is closely related to the following 2 important concepts associated with the development and application of risk models for congenital and pediatric cardiac care: (1) the point in time of assessing risk with a risk model and (2) the outcomes measured with a risk model.

A risk model is a mathematical formula that can be used to predict the probability that a given outcome will occur. Whenever one is developing or using a risk model, it is important to consider the purpose of the analysis. Risk models can be used to predict the risk of a given patient, assess the case mix of a given program, or even assess the performance of a given program in comparison with multi-institutional aggregate outcome data.

First, the point in time of assessing this risk is critical in each of these applications. The Society of Thoracic Surgeons Congenital Heart Surgery Database (STS CHSD) currently assesses outcomes with the 2014 STS CHSD Mortality Risk Model, ${ }^{2-5}$ which facilitates description of

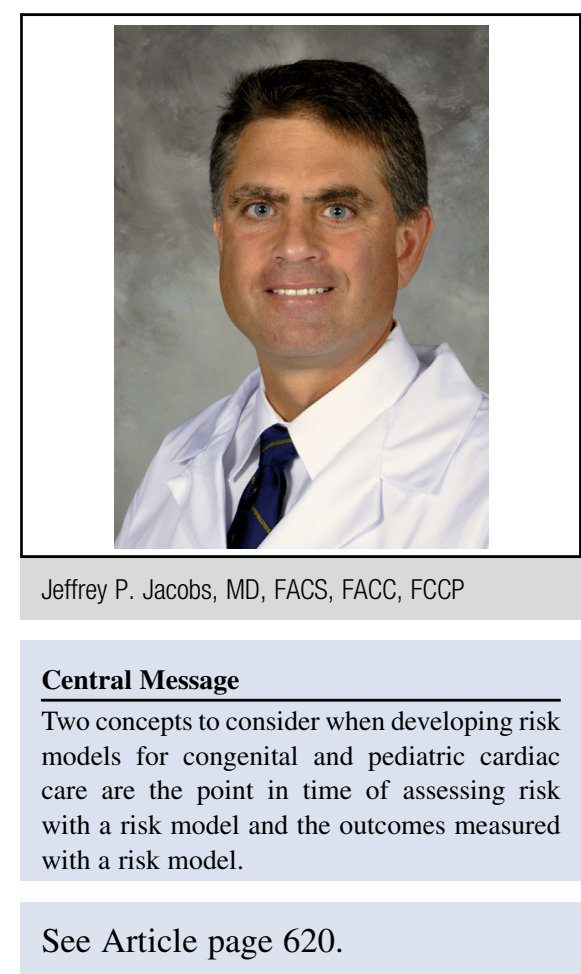

operative mortality adjusted for the both procedural and for patient-level factors. The 2014 STS CHSD Mortality Risk Model is designed to assess risk at the time that the patient enters the operating theater. ${ }^{2-5}$ Meanwhile, models that include early postoperative parameters present on arrival to the intensive care unit (such as postoperative hypoxia, ${ }^{6}$ postoperative arterial blood lactates, ${ }^{6}$ and data contained in the PRISM score ${ }^{1}$ ) may better inform a model designed to assess risk at the time that the patient enters the intensive care unit after surgery and to assess intensive care unit performance. $^{7}$

Second, the outcomes measured with a risk model require careful consideration. The 2014 STS CHSD Mortality Risk Model uses the outcome of operative mortality. As stated in the article by Berger and colleagues, "Outcome prediction for pediatric heart surgery has focused on mortality, but mortality has been significantly reduced over the last 2 decades. Clinical care practices now emphasize reducing morbidity." Consequently, efforts by STS are ongoing to develop a multidomain composite score that incorporates both mortality and morbidity and adjusts for the operation performed and patient-specific factors. Funded by the US 
National Heart, Lung and Blood Institute, a National Institutes of Health and National Heart, Lung and Blood Institute R01 grant (R01 HL122261) is actively developing this multidomain composite (principal investigator, Sara K. Pasquali; STS principal investigator, Jeffrey P. Jacobs). Titled "Understanding Quality and Costs in Congenital Heart Surgery," this grant has two specific aims: (1) to develop and validate a composite quality metric in congenital heart surgery; and (2) to examine the relationship between our composite measure of quality and cost. This new multidomain composite will add to the portfolio of measures available for risk adjustment in pediatric and congenital cardiac surgery and complement currently available measures, including the 2014 STS-CHSD Mortality Risk Model.

Berger and colleagues ${ }^{1}$ have demonstrated that "New, functional morbidity is associated with surgical complexity and can be predicted with mortality by a physiology-based algorithm." Lessons learned from this analysis include the importance of both the point in time of assessing risk with a risk model and the outcomes measured with a risk model.

\section{References}

1. Berger JT, Holubkov R, Reeder R, Wessel DL, Meert M, Berg RA, et al. Morbidity and mortality prediction in pediatric heart surgery: physiological profiles and surgical complexity. J Thorac Cardiovasc Surg. 2017;154: 620-8.

2. Jacobs JP, O’Brien SM, Pasquali SK, Kim S, Gaynor JW, Tchervenkov CI, et al. The importance of patient-specific preoperative factors: an analysis of the Society of Thoracic Surgeons Congenital Heart Surgery Database. Ann Thorac Surg. 2014; 98:1653-8; discussion 1658-9.

3. O'Brien SM, Jacobs JP, Pasquali SK, Gaynor JW, Karamlou T, Welke KF, et al. The Society of Thoracic Surgeons Congenital Heart Surgery Database Mortality Risk Model: part 1-statistical methodology. Ann Thorac Surg. 2015;100: 1054-62.

4. Jacobs JP, O’Brien SM, Pasquali SK, Gaynor JW, Mayer JE Jr, Karamlou T, et al. The Society of Thoracic Surgeons Congenital Heart Surgery Database Mortality Risk Model: part 2—clinical application. Ann Thorac Surg. 2015;100:1063-8; discussion 1068-70.

5. Pasquali SK, Jacobs ML, O'Brien SM, He X, Gaynor JW, Gaies MG, et al. Impact of patient characteristics on hospital-level outcomes assessment in congenital heart surgery. Ann Thorac Surg. 2015;100:1071-6; discussion 1077.

6. Ranucci M, Pistuddi V, Pisani GP, Carlucci C, Isgrò G, Frigiola A, et al; on behalf of the Surgical and Clinical Outcome Research (SCORE) Group. Retuning mortality risk prediction in paediatric cardiac surgery: the additional role of early postoperative metabolic and respiratory profile. Eur J Cardiothorac Surg. 2016;50: 642-9.

7. Jacobs JP. Risk adjustment in paediatric and congenital cardiac surgery. Eur J Cardiothorac Surg. 2016;50:650-1. 